\section{References}

1. Zhang YX, Liu JR, Jiang B, et al. Lance-Adams Syndrome: a report of two cases. Journal of Zhejiang University Science, 2007; 8: 71520.

2. Russell D. Rollinson, Bernard S. Gilligan. Postanoxic action myoclonus (Lance-Adams syndrome) responding to valproate. Arch Neurol, 1979: 36; 44-45.

3. Kowalczyk EE, Koszewicz MA, Budrewicz SP, Podemski $\mathrm{R}$, Slotwinski K. LanceAdams syndrome in patient with anoxic encephalopathy in the course of bronchial asthma. Wiadomosci Lekarskie, 2006; 59:5602.
4. Reed LJ, Marsden P, Lasserson D. et al. FDG-PET analysis and findings in amnesia resulting from hypoxia. Memory, 1999 Sep-Nov; 7(5-6): 599-612.

5. Werhahn KJ, Brown P, Thompson PD, Marsden CD. The clinical features and prognosis of chronic posthypoxic myoclonus. Mov Disord, 1997 Mar; 12(2): 216-20.

6. Wijdicks EF, Parisi JE, Sharbrough FW. Prognostic value of myoclonus status in comatose survivors of cardiac arrest. Annals of Neurology, 1994; 35: 239-43.

\title{
Posterior Reversible Encephalopathy Syndrome in a patient with pregnancy-induced hypertension in puerperium
}

\author{
Sibly AJM, Caldera HPMC, Gamage R \\ Institute of Neurology, National Hospital of Sri Lanka, Colombo, Sri Lanka
}

Correspondence: Dr.A.J.M. Sibly (mohamedshibly@rocketmail.com)

\section{Introduction}

Posterior reversible encephalopathy syndrome (PRES) is a clinical-neuroradiological entity characterized by headache, vomiting, altered mental status, blurred vision and seizures as well as images suggesting white-gray matter edema involving, in most cases, posterior region of the central nervous system. PRES is commonly associated with hypertensive encephalopathy, preeclampsiaeclampsia, and immunosuppressive and cytotoxic drugs. While usually reversible, the early recognition and treatment of this syndrome is important to prevent permanent neurological sequelae. Treatment is based on the management or withdrawal of the triggering factor. We present a patient who developed pregnancy-induced hypertension after delivery and subsequently PRES, and made an uneventful recovery with prompt management of hypertension and seizures.

\section{Case Report}

Mrs. HS, 30-year-old woman was admitted to Colombo North teaching hospital, with one day history of worsening headache, vomiting, restlessness and altered level of consciousness. There was no history of fever.

She had given birth to her $1^{\text {st }}$ baby seven days earlier. Her antenatal period was uneventful and there was no history of hypertension during that period, at delivery, or after delivery until she was discharged home on the $3^{\text {rd }}$ day after delivery. There was no significant past medical history such as epilepsy, hypertension or connective tissue disorders.

On admission to ETU, she was drowsy and confused with a GCS of 13. There was no neck stiffness. She had mild bilateral pitting ankle edema and her blood pressure was 170/100 $\mathrm{mmHg}$. She had generalized heperreflexia and bilateral upgoing plantars. Examination of her optic fundi was normal. 
She developed three episodes of generalized tonic clonic seizures and then remained in a state of altered level of consciousness. Her seizures were managed with IV boluses of diazepam and IV magnesium sulfate infusion. She was also started on IV cefotaxime and phenytoin sodium. An electroencephalogram could not be obtained at her initial presentation.

She underwent a non-contrast CT-Brain which revealed vague hypodense areas in both occipital lobes which were thought to be infarcts (Figure 1).

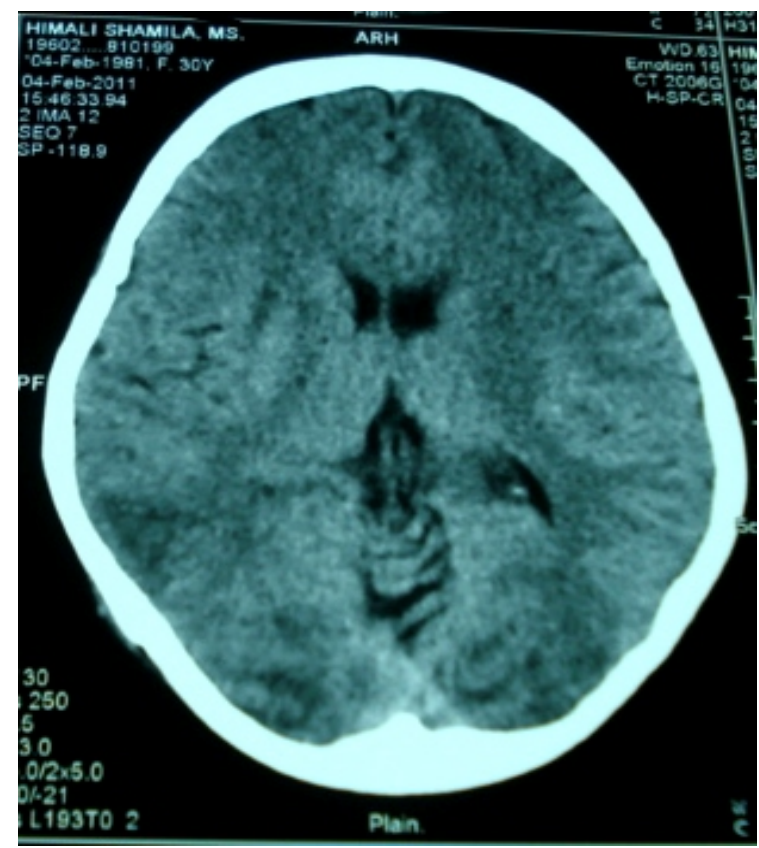

Figure 1: Non-contrast CT brain shows vague hypodense areas in the occipital poles resembling infarcts.

She was transferred to neurology unit, NHSL, Colombo for further investigations and management about 12 hours after the initial presentation with the provisional diagnosis of cerebral venous sinus thrombosis.

On admission to the Neurology unit, she was conscious though disorientated with a GCS of 14 . Her BP was $160 / 90 \mathrm{mmHg}$. There were no new neurological signs. Her mental state gradually recovered to normal after about $48 \mathrm{hrs}$. She was started on nifedipine SR and phenytoin and cefotaxime were continued.
Haematological and Biochemical tests were as follows:

$\begin{array}{ll}\mathrm{Hb} & -14.1 \mathrm{~g} / \mathrm{dL} \quad \mathrm{PCV}-39.1 \% \\ \mathrm{WBC} & -11000 / \mathrm{mm}^{3}(\mathrm{~N}-75.6 \%, \mathrm{~L}-15.3 \%) \\ \text { Platelets }-321,000 / \mathrm{mm}^{3} \\ \text { ESR } \quad-08 \mathrm{~mm}\end{array}$

Urine Albumin - Trace

S. Creatinine $\quad-82 \mu \mathrm{mol} / \mathrm{L}$

Blood Urea $\quad-3.8 \mathrm{mmol} / \mathrm{L}$

$\mathrm{Na}^{+} \quad-142 \mathrm{mmol} / \mathrm{L} \quad \mathrm{K}^{+} \quad-3.4 \mathrm{mmol} / \mathrm{L}$

AST $-52 \mathrm{u} / \mathrm{L} \quad$ ALT $-70 \mathrm{u} / \mathrm{L}$

S.Protein $-68 \mathrm{~g} / \mathrm{L}$

Albumin - $36 \mathrm{~g} / \mathrm{L}$

ANA - Negative

She underwent MRI scan of the brain which showed ill defined areas of low signal intensity in T1weighted images and high signal intensity in T2weighted and FLAIR images in cortical and subcortical white matter in the bilateral occipital and parietal lobes (Figure 2). Both MRA and MRV of the brain were normal with no evidence of cerebral vasoconstriction or cerebral venous sinus thrombosis. These appearances were in favour of PRES.

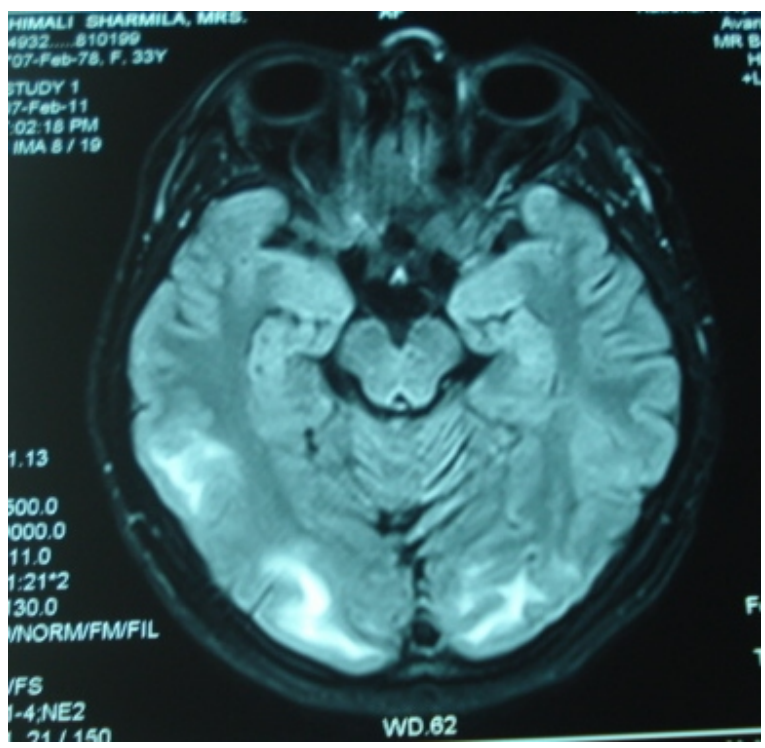

Figure 2: Areas of hypodense signals in the white matter of occipital and right parietal lobes on MRI T2-weighted FLAIR images. 
The EEG performed during her recovery period did not reveal any abnormalities.

USS Abdomen revealed normal kidneys with no evidence of renal artery stenosis in Doppler studies. There were no suprarenal masses.

During her stay in the neurology unit, there were no further seizures, and she made a complete recovery within a few days. She was discharged on nifedipine SR (on discharge, her BP was 140/80 $\mathrm{mmHg}$ ) and phenytoin on the $8^{\text {th }}$ day after admission.

\section{Discussion}

PRES is a clinical-neuroradiological entity, initially described in 1996 as reversible posterior leukoencephalopathy syndrome (1). This syndrome is characterised by headache, visual disturbances, seizures, altered mental status and radiological findings of oedema in the white matter of the brain areas perfused by the posterior brain circulation. While most cases are due to systemic hypertension, other conditions and entities have been identified as etiologic or risk factors in the absence of hypertension, such as immunosuppressant drugs use, nephrotic state, sepsis, and systemic lupus erythematosus (1 - 4).

The definite identification of this syndrome is achieved with head MRI (5). More invasive procedures such as LP are neither necessary nor recommended. The main features detected in MRI are high density areas suggestive of cerebral oedema, mostly in the posterior white matter of the brain, although anterior structures and gray matter may also be involved.

The treatment of PRES, as a secondary pathology, depends upon the determination of the underlying contributing condition; however, therapy for symptoms that might worsen the outcome (e.g. seizures) must be provided, as well as strictly monitored BP control.

Though the incidence of PRES is more commonly associated with Pregnancy-Induced Hypertension (PIH) before delivery, there are reported cases of PRES occurring in women who developed PIH after delivery $(6,7)$ and our patient belongs to this category.
With prompt management of seizures and hypertension, she completely recovered without any sequelae. Her progress was monitored with clinical signs and symptoms and we didn't arrange for a follow up MRI scan as resolution of oedema was expected.

\section{References}

1. Hinchey J, Chaves C, Appignani B, Breen J, Pao L, Wang A, et al. A reversible posterior leukoencephalopathy syndrome. NEnglJMed, 1996; 334: 494-500.

2. Ishikura K, Ikeda M, Hamasaki Y, Hataya H, Nishimura G, Hiramoto R, et al. Nephrotic state as a risk factor for developing posterior reversible encephalopathy syndrome in paediatric patients with nephrotic syndrome. Nephrol Dial Transplant, 2008; 23: 2531-6.

3. Bartynski WS, Boardman JF, Zeigler ZR, Shadduck RK, Lister J. Posterior reversible encephalopathy syndrome in infection, sepsis and shock. Am J Neuroradiol, 2006; 27: 2179-90.

4. El Karoui K, Le Quintrec M, Dekeyser E, Servais A, Hummel A, Fadel F, et al. Posterior reversible encephalopathy syndrome in systemic lupus erythematosus. Nephrol Dial Transplant, 2008; 23: 757-63.

5. Covarrubias DJ, Luetmer PH, Campeau NG. Posterior reversible encephalopathy syndrome: prognostic utility of quantitative diffusion-weighted MR images. $A m J$ Neuroradiol, 2002; 23: 1038-48.

6. Peng WX, Nakaii M, Matsushima T, Asakura H. Atypical case of reversible posterior leucoencephalopathy syndrome associated with puerperal HELLP syndrome. Arch Gynecol Obstet, 2008; 278: 269-71.

7. Morelli N, Gori S, Michelassi MC, Falorni M, Cafforio G, Bianchi MC, et al. Atypical posterior reversible encephalopathy syndrome in puerperium. Eur Neurol, 2008; 59: 195-7. 